\title{
Correlation and Divergence Analysis for Phenotypic Traits in Sesame (Sesamum indicum L.) Genotypes
}

\author{
Gadisa Hika $^{1}$, Negash Geleta ${ }^{2^{*}}$ and Zerihun Jaleta ${ }^{2}$ \\ ${ }^{1}$ Arjo Preparatory school, P.O. Box: 10, Arjo, East Wollega, Ethiopia \\ ${ }^{2}$ Department of Plant Sciences, College of Agriculture and Natural Resources, Wollega University, \\ P.O. Box: 395, Nekemte, Ethiopia
}

\begin{abstract}
A study was conducted to determine the magnitude of associations of traits and genetic divergence among the 64 sesame genotypes. The genotypes were arranged in $8 \times 8$ simple lattice design and grown in Arjo district, Western Ethiopia during 2013 cropping season. Data were recorded for 12 phenotypic traits and analyzed using SAS software version 9.20 (2002, USA). The results showed that seed yield had positive and significant genotypic and phenotypic correlations with all traits, indicating they are important yield components and can be used for yield improvement in sesame breeding program except for $\mathrm{PH}$ and BY. Further analysis by path coefficient method indicated that at genotypic level DM, CFP and HI exerted high positive direct effects on seed yield and strong and positive correlation with seed yield. Similarly, at phenotypic level positive and high direct effects were exerted by CFP, NPB and $\mathrm{HI}$ on seed yield and these traits had also strong positive associations with SY. Genetic distance analysis showed that the 64 sesame genotypes were grouped in to 4 clusters and maximum inter cluster square distance $\left(D^{2}\right)$ was recorded between cluster I and II followed by cluster I and III. Hence crossing involving cluster I with II and cluster I and III may exhibit high heterotic values and could give transgressive segregants. The principal component analysis revealed that four principal components explained about $66 \%$ of the total variation existed among the genotypes. The dominant seed color observed was brown followed by white in the genotypes. The study generally indicated that there was significance genetic variability or divergence among the genotypes. Thus, there is enormous opportunity to use the existing genotypes for direct selection as well as using distant parents for crossing purposes to improve specific traits.
\end{abstract}

Copyright@2014 STAR Journal. All Rights Reserved.

\author{
Article Information \\ Article History: \\ Received : 19-10-2014 \\ Revised : 21-12-2014 \\ Accepted : 27-12-2014 \\ Keywords: \\ Correlation \\ Divergence analysis \\ Genotypes \\ Path analysis \\ Sesame
}

*Corresponding Author:

Negash Geleta

E-mail:

ayananegash@yahoo.com

\section{INTRODUCTION}

Sesame (Sesamum indicum L.) is a diploid species with $2 x=2 n=26$ chromosomes. It is a self pollinated crop, belongs to the Pedaliaceae family, containing 60 species organized into 16 genera (Ashri 1998; Zhang et al., 2013). The genus Sesamum comprises of 36 species (Kobayashi, 1981). Sesamum indicum L. is the most commonly cultivated species (Nayar and Mehra, 1970). It is the oldest oilseed crop known to man and is now grown in many parts of the world (Bedigian and Harlan, 1986); and it is currently grown in more than 50 countries in the world. India ranks first in production and one third of the world production and nearly $30 \%$ of the sesame acreage in the world is from India. Sesame is a small farmers' crop in the developing countries and it is grown in the small plots (Gulhan et al., 2004).

Sesame is adapted in tropical to the temperate zones from about $40^{\circ} \mathrm{N}$ to $40^{\circ} \mathrm{S}$ latitude. It grows best on the areas between an altitude of 500 and 800 masl and it can grow even up to 1250 masl on well drained soils of moderate fertility. It is an annual occasionally perennial crop. It needs a growing period of 70 to 150 days; usually 100 to 120 days. The optimum $\mathrm{pH}$ for growth ranges from 5.4 to 6.7 . Good drainage is crucial, as sesame is very susceptible to short periods of water logging. It is intolerant of very acidic or saline soils. The optimum temperature for growth varies with cultivar in the range 27 to $35^{\circ} \mathrm{C}$. Periods of high temperature above $40^{\circ} \mathrm{C}$ during flowering reduce number of capsule and seed development. It requires from 600 to $1000 \mathrm{~mm}$ amount of water (Nath et al., 2000).

Sesame seed is used for confectionery purpose and an important source of edible oil and is also widely used as a spice. The seed contains 50 to $60 \%$ oil which has excellent stability due to the presence of natural antioxidants such as sesamolin, sesamin and sesamol (Brar and Ahuja, 1979).The fatty acid composition of sesame oil varies considerably among the different cultivars worldwide (Yermanos et al., 1972). In addition, it is used as pharmaceutical and skin care products and as a synergist for insecticides (Salunkhe and Desai, 1986). 
Gadisa Hika et al.,

Generally $100 \%$ of the world production area is found in developing countries with largest area in India, Myanmar, China, Nigeria, and Uganda (FAO, 1995). Total world production of sesame in 2005 was in 9.35 million hectare with 3.7 million metric tons, $70 \%$ of which was produced in Asia and $26 \%$ in Africa (FAO, 2005). Sesame is a valuable crop for Ethiopia both for local uses and export market. Ethiopia is the $7^{\text {th }}$ major sesame producing country in the world and has an export share of $5.1 \%$. There are around 21 countries that are major importers of sesame from Ethiopia. In 1999, Ethiopia exported about 30,000 tons of sesame worth 28 million USD. The total area under sesame in Ethiopia is estimated at $384,682.79$ hectare and production is about $327,740.922$ tones and productivity is about 0.852 ton/ha (CSA, 2011).

The average productivity of sesame is low as compared to other oilseeds due to the lack of high yielding cultivars, resistant to major insect pests and diseases and shattering problem. Since sesame has been treated as less input intensive crop, the role of breeding improved varieties has been considered as promising approach (Ashri, 1988). But there is a potential harvest reported elsewhere, as of $3.6 \mathrm{t} / \mathrm{ha}$ in Nigeria (Uzo and Ojiake, 1981). Like other crops, productivity and associated increase in production of sesame could be achieved through development of improved varieties which have less shattering problem with better cultural practices. Selection of germplasms for desirable traits needs thorough studies about the manner of traits interrelationships and divergence among the populations. Selection is an integral part of breeding program by which genotypes with high productivity in a given environment are selected. However, selection for high yield is made difficult by the complex nature of this trait (Singh and Singh, 1973; Sastri, 1974); it is highly influenced by environment, which reduces the progress to be achieved through direct selection. In such cases, indirect selection techniques are more promising to improve the economic trait. This selection criterion takes into account the information on interrelationship among agronomic characters, their relationship with grain yield as well as their direct influence on grain yield (Dewey and Lu, 1959). In addition, knowledge on the extent and pattern of genetic divergence present in a population is absolutely essential for further improvement of the crop. Hence the objectives of the study were to estimate the magnitude of interrelationships among yield and yield related traits of sesame genotypes; and to estimate the extent of genetic divergence among sesame accessions.

\section{MATERIALS AND METHODS}

\section{Experimental Site}

The experiment was carried out at Jima Arjo district, Eastern Wollega Zone of Oromia Regional State, Western Ethiopia during 2013 cropping season. Jima Arjo district is $378 \mathrm{~km}$ to the west of Addis Ababa and $48 \mathrm{~km}$ away from the Nekemte town. The area is located at an altitudinal ranges from 1200-1816 masl. The area receives an average annual rainfall that ranges from $824-2616$ $\mathrm{mm}$. The average annual temperature ranges from 18$26^{\circ} \mathrm{C}$ (Source: Jima Arjo Agricultural Office).

\section{Experimental Materials and Design}

The experimental material consisted of 64 sesame genotypes that were collected from the Institute of
Sci. Technol. Arts Res. J., Oct-Dec 2014, 3(4): 01-09

Biodiversity Conservation (IBC) (Table 1). The trial was laid out in 8x 8 simple lattice design. Seeds of each genotype was sown in rows by hand on a separate plot size of $6.4 \mathrm{~m}^{2}$ ( 4 rows $\times 4 \mathrm{~m}$ row length $\times 40 \mathrm{~cm}$ between rows and $10 \mathrm{~cm}$ between plants with in rows). Other cultural practices were followed as recommended for the area and no fertilizer was applied.

\section{Data Collection}

Data were collected for days to $50 \%$ flowering, days to $90 \%$ maturity, capsule filling period, plant height, number of branches per plant, number of primary branches per plant, number of capsules per plant, thousand seed weight, biomass yield, seed yield, harvest index, and seed color.

\section{Data Analysis}

\section{Correlation Analysis}

Estimation of the phenotypic and genotypic correlation coefficients were computed following the procedures suggested by Miller et al. (1958) and adopted by Dabholkar (1992) from corresponding variance and covariance components. The significance of phenotypic correlation coefficients was tested by the formula of Singh and Chaudhary (1985); whereas the significance of genotypic correlation coefficient is tested using the formula described by Robertson (1959).

\section{Path Coefficient Analysis}

In path coefficient analysis, direct and indirect effects of the independent characters on dependent character (seed yield) was estimated following the procedures of Dewey and Lu (1959).

\section{Genetic Divergence Analysis}

Genetic divergence analysis was computed based on multivariate analysis using Mahalanobis's $D^{2}$ statistic (Mahalanobis, 1936) using SAS Software program (SAS, 2002, Version 9.0, USA). Squared distance $\left(D^{2}\right)$ for pairs of genotypes was computed using the following formula: $\mathrm{D}^{2} \mathrm{ij}=(\mathrm{Xi}-\mathrm{Xj}) / \mathrm{S}^{-1}(\mathrm{Xi}-\mathrm{Xj})$; Where, $\mathrm{D}^{2} \mathrm{ij}=$ the square distance between any two genotypes $\mathrm{i}$ and $\mathrm{j}, \mathrm{Xi}$ and $\mathrm{Xj}=$ the vectors for the values for genotypes $i^{\text {th }}$ and $j^{\text {th }}$, and $S^{-1}$ $=$ the inverse of pooled variance covariance matrix. Based on the squared distances $\left(D^{2}\right)$ values, clustering of genotypes was done using Tocher's method as described by Singh and Chaudhary (1999).

\section{Principal Component Analysis}

Principal component analysis (PCA) was used to find out the characters, which accounted more to the total variation. The data were standardized to mean zero and variance of one before computing principal component analysis. Principal components based on correlation matrix were calculated using SAS software.

\section{RESULTS}

\section{Correlations among Agronomic Traits}

Estimates of phenotypic and genotypic correlation coefficients between each pair of characters are presented in Table 2. The magnitudes of genotypic correlation coefficients for most of the characters were higher than their corresponding phenotypic correlation coefficients, except in few cases, which indicate the presence of inherent or genetic association among various characters. Seed yield showed positive and significant correlations with DF, DM, PB, BPP, CPP, TSW and $\mathrm{HI}$ at both genotypic and phenotypic levels and 
Table 1: List of sesame genotypes used for the study

\begin{tabular}{|c|c|c|c|c|c|}
\hline No & Accession Code & Region & Zone & District & Altitude \\
\hline 1 & 9242 & Oromiya & Misrak Harerge & Goro Gutu & 1620 \\
\hline 2 & 202286 & Amhara & Semen Shewa & Kewet & 1490 \\
\hline 3 & 202287 & Amhara & Oromiya & Artuma Fursina Jile & 1730 \\
\hline 4 & 202288 & Amhara & Oromiya & Artuma Fursina Jile & 1770 \\
\hline 5 & 202289 & Amhara & Oromiya & Artuma Fursina Jile & 1770 \\
\hline 6 & 202306 & Amhara & Oromiya & ChefeGolanaDewerah & 1510 \\
\hline 7 & 202308 & Amhara & Oromiya & Chefe Golana ewerah & 1455 \\
\hline 8 & 202309 & Amhara & Oromiya & ChefeGolanaDewerah & 1440 \\
\hline 9 & 202312 & Amhara & Oromiya & Chefe olana Dewerah & 1393 \\
\hline 10 & 202313 & Amhara & Oromiya & Chefe olana Dewerah & 1390 \\
\hline 11 & 202315 & Amhara & Oromiva & Chefe olana Dewerah & 1445 \\
\hline 12 & 202317 & Amhara & Oromiya & Chefe Golana ewerah & 1355 \\
\hline 13 & 202318 & Amhara & Debub Wello & Kalu & 1525 \\
\hline 14 & 202320 & Amhara & Oromiya & Bati & 1505 \\
\hline 15 & 202323 & Amhara & Oromiva & Bati & 1585 \\
\hline 16 & 202327 & Amhara & Oromiya & Bati & 1470 \\
\hline 17 & 202329 & Amhara & Oromiya & Bati & 1420 \\
\hline 18 & 202330 & Amhara & Debub Wello & Werebabu & 1430 \\
\hline 19 & 202332 & Amhara & Debub Wello & Werebabu & 1690 \\
\hline 20 & 202335 & Amhara & Debub Wello & Werebabu & 1360 \\
\hline 21 & 202339 & Amhara & Debub Wello & Tehuledere & 1645 \\
\hline 22 & 202343 & Amhara & Semen Wello & Habru & 1580 \\
\hline 23 & 202345 & Amhara & Semen Wello & Habru & 1565 \\
\hline 24 & 202353 & Amhara & Semen Wello & Guba Lafto & 1640 \\
\hline 25 & 202356 & Amhara & Semen Wello & Guba Lafto & 1770 \\
\hline 26 & 202360 & Amhara & Semen Wello & Guba Lafto & 1675 \\
\hline 27 & 202364 & Amhara & Semen Wello & Guba Lafto & 1520 \\
\hline 28 & 202370 & Amhara & Semen Wello & Kobo & 1590 \\
\hline 29 & 202373 & Amhara & Semen Wello & Kobo & 1790 \\
\hline 30 & 202374 & Amhara & Semen Shewa & Efratana Gidim & 1395 \\
\hline 31 & 202511 & Amhara & Semen Shewa & Not Available & 1475 \\
\hline 32 & 203099 & SNNP & Gurage & Goro & 1240 \\
\hline 33 & 203104 & Oromiya & Jimma & Sokoru & 1400 \\
\hline 34 & 211921 & Amhara & Misrak Gojam & Dejen & 1600 \\
\hline 35 & 212632 & Amhara & Debub Wello & Ambasel & 1460 \\
\hline 36 & 212633 & Amhara & Debub Wello & Ambasel & 1540 \\
\hline 37 & 212994 & SNNP & Bench Maji & Dirashe Special & 1270 \\
\hline 38 & 212995 & SNNP & Semen Omo & Gofa Zuria & 1290 \\
\hline 39 & 214254 & Amhara & Semen Gondar & Addi Arkay & 1630 \\
\hline 40 & 215816 & Oromiya & Misrak Wellega & Diga Leka & 1435 \\
\hline 41 & 216896 & Oromiya & Arssi & Merti & 1570 \\
\hline 42 & 228816 & Oromiya & Misrak Harerge & Babile & 1500 \\
\hline 43 & 235405 & Tigray & Debubawi & Rayaazebo & 1650 \\
\hline 44 & 241291 & Amhara & Debub Wello & Kalu & 1500 \\
\hline 45 & 241992 & Amhara & Debub Wello & Kalu & 1660 \\
\hline 46 & 241293 & Amhara & Debub Wello & Kalu & 1550 \\
\hline 47 & 241294 & Amhara & Oromiya & Bati & 1380 \\
\hline 48 & 241295 & Amhara & Oromiya & Bati & 1380 \\
\hline 49 & 241296 & Amhara & Oromiya & Bati & 1350 \\
\hline 50 & 241297 & Amhara & Oromiya & Bati & 1280 \\
\hline 51 & 241298 & Amhara & Oromiya & Bati & 1280 \\
\hline 52 & 241299 & Amhara & Oromiya & Bati & 1750 \\
\hline 53 & 241300 & Amhara & Oromiya & Bati & 1500 \\
\hline 54 & 241301 & Amhara & Oromiya & Chefe olana Dewerah & 1600 \\
\hline 55 & 241302 & Amhara & Oromiya & Chefe olana Dewerah & 1450 \\
\hline 56 & 241303 & Amhara & Oromiya & Artuma Fursina Jile & 1800 \\
\hline 57 & 241304 & Amhara & Oromiya & Artuma Fursina Jile & 1750 \\
\hline 58 & 241305 & Tigray & Mirabawi & Tahtay Adiyabo & 1200 \\
\hline 59 & 241314 & Amhara & Semen Gondar & Addi Arkay & 1460 \\
\hline 60 & 241320 & Amhara & Semen Gondar & Lay Armacho & 1300 \\
\hline 61 & 241328 & Amhara & Semen Gondar & Sanja & 1230 \\
\hline 62 & 241329 & Amhara & Semen Gondar & Alefa & 1400 \\
\hline 63 & 241347 & Amhara & Semen Gondar & Belesa & 1700 \\
\hline 64 & 241348 & Amhara & Semen Gondar & Belesa & 1700 \\
\hline
\end{tabular}

significant and positive correlation with CFP at genotypic level. Therefore, from the correlation analysis it can be confirmed that DF, DM, CFP, PB, BPP, CPP, TSW and HI were found to be important yield related traits. Most phenologic and vegetative characters showed positive and significant correlations among themselves. Similarly, yield components also showed in most cases positive and significant correlations among each other at genotypic 
Gadisa Hika et al.,

and phenotypic levels. Number of branches per plant exhibited positive and significant genotypic and phenotypic correlations with DF, DM, PB, TSW; and $\mathrm{HI}$ at both genotypic and phenotypic levels; and it had significant and positive correlation with $\mathrm{CFP}$, and $\mathrm{PH}$, at genotypic level.

Number of capsule per plant had positive and significant genotypic and phenotypic correlations with CFP, PH, PB and TSW; and it had positive and significant correlation with days to $50 \%$ flowering, at genotypic level only. Biomass yield had positive and significant genotypic and phenotypic correlations with days to $50 \%$ flowering,
Sci. Technol. Arts Res. J., Oct-Dec 2014, 3(4): 01-09

days to $90 \%$ maturity, and plant height while it had negative and significant correlation with harvest index. These indicate that these traits can be improved simultaneously through selection except for harvest index. Thousand seed weight had significant and positive genotypic and phenotypic correlations with capsule filling period, plant height and number of branches per plant, number of primary branches per plant; and it had positive and significant correlations with harvest index at genotypic level only. Generally, positive and significant association of pairs of characters at phenotypic and genotypic level justified the possibility of correlated response to selection.

Table 2: Genotypic (above diagonal) and phenotypic (below diagonal) correlation coefficients among seed yield and other traits

\begin{tabular}{|c|c|c|c|c|c|c|c|c|c|c|c|}
\hline Traits & DF & DTM & CFP & PH & PB & BPP & CPP & TSW & BY & SY & HI \\
\hline DF & & $0.847^{\star * *}$ & $0.456^{\star *}$ & $0.691^{\star *}$ & $0.825^{\star *}$ & $0.866^{* *}$ & $0.404^{\star \star}$ & 0.116 & $0.569^{\star *}$ & $0.753^{* *}$ & $0.702^{\star \star}$ \\
\hline DM & $0.77^{\star \star}$ & & 0.043 & $0.307^{\star}$ & $0.678^{* *}$ & $0.598^{* *}$ & 0.077 & 0.119 & $0.913^{* *}$ & $0.878^{\star *}$ & $0.576^{\star *}$ \\
\hline CFP & $0.306^{\star}$ & 0.005 & & $0.868^{* *}$ & 0.297 & $0.465^{\star *}$ & $0.905^{\star *}$ & $0.354^{*}$ & 0.145 & $0.429^{\star *}$ & 0.079 \\
\hline PH & $0.582^{\star *}$ & 0.167 & $0.867^{\star \star}$ & & $0.391^{*}$ & $0.457^{* *}$ & $0.861^{* *}$ & $0.925^{\star *}$ & $0.832^{* *}$ & 0.075 & $0.383^{*}$ \\
\hline PB & $0.742^{\star *}$ & $0.533^{\star *}$ & 0.148 & 0.239 & & $0.931^{* *}$ & $0.482^{\star *}$ & $0.689^{\star *}$ & 0.059 & $0.482^{\star \star}$ & $0.937^{\star \star}$ \\
\hline BPP & $0.868^{\star *}$ & $0.5^{\star \star}$ & $0.341^{*}$ & 0.291 & $0.931^{* \star}$ & & $0.364^{*}$ & $0.583^{\star *}$ & 0.043 & $0.503^{\star \star}$ & $0.865^{\star \star}$ \\
\hline CPP & 0.229 & 0.013 & $0.826^{\star *}$ & $0.817^{\star *}$ & $0.351^{*}$ & 0.218 & & $0.974^{\star *}$ & 0.223 & $0.639^{\star \star}$ & $0.385^{\star}$ \\
\hline TSW & 0.026 & 0.028 & 0.196 & $0.895^{\star *}$ & $0.576^{* *}$ & $0.453^{\star *}$ & $0.963^{\star \star}$ & & 0.149 & $0.515^{\star \star}$ & $0.432^{\star \star}$ \\
\hline BY & $0.412^{\star \star}$ & $0.873^{\star *}$ & 0.059 & $0.809^{\star *}$ & 0.012 & 0.007 & 0.095 & 0.046 & & 0.041 & $-0.755^{\star *}$ \\
\hline SY & $0.654^{\star *}$ & $0.824^{\star *}$ & 0.268 & 0.011 & $0.473^{* *}$ & $0.485^{\star \star}$ & $0.509^{\star *}$ & $0.352^{*}$ & 0.005 & & $0.399^{*}$ \\
\hline HI & $0.576^{\star *}$ & $0.424^{\star \star}$ & 0.024 & 0.209 & $0.91^{\star *}$ & $0.789^{\star \star}$ & 0.233 & 0.28 & $-0.766^{\star *}$ & $0.385^{\star}$ & \\
\hline
\end{tabular}

${ }^{*},{ }^{* *}=$ Significant at $5 \%$ and $1 \%$ probability level, respectively. DF = Days to $50 \%$ flowering, DM = Days to maturity, CFP = Capsule filling period, $\mathrm{PH}=\mathrm{Plant}$ height $(\mathrm{cm}), \mathrm{PB}=$ Number of primary barnches per plant, BPP = Number of branches per plant, CPP $=$ Number of Capsules per plant, $\mathrm{SY}=$ Seed yield $(\mathrm{kg} / \mathrm{h}), \mathrm{BY}=$ Biomass yield $(\mathrm{kg} / \mathrm{h}), \mathrm{SW}=1000$ seed weight $(\mathrm{g})$.

\section{Path Coefficient Analysis}

In the present study, based on their correlation coefficients, 10 independent variables that have direct relationship with seed yield were included in the path analysis. The phenotypic and genotypic correlations were partitioned in to direct and indirect effects using seed yield as a dependent variable separately. The genotypic direct and indirect effects of different characters on seed yield are presented in Table 3. Positive and high direct effect was exerted by DM, CFP, BPB, and $\mathrm{HI}$ on seed yield while negative and high direct effect was exerted by DF, NPB and CPP. The high significant correlation coefficient between seed yield and DF was due to its high indirect effects through DM and CFP on seed yield. The high positive correlation coefficient between seed yield and CPP was due the large indirect effects of CFP and HI. Similarly, DM, CFP and $\mathrm{HI}$ had high positive direct effects on seed yield and also they have strong correlation with seed yield indicating the most important yield components at genotypic level. The residual effect $8.74 \%$ indicates that characters which are included in the genotypic path analysis explained $91.26 \%$ of the total variation in seed yield.

Positive and high direct effects on seed yield were observed at phenotypic level by CFP, PH, NPB, BY and $\mathrm{HI}$ while negative and high direct effect on seed yield were observed by DF, DM BPP, CPP, and TSW (Table 4). The positive and significant correlation coefficients of DF and DM with SY were due to the positive indirect effects of CFP, PH, NPB, BY and HI through DF on SY. Similarly, CFP, NPB, and $\mathrm{HI}$ had strong positive correlation as well positive direct effects on SY indicating they are more importantly related to SY at phenotypic level. The residual effect determines unaccounted variability of the dependent factor (seed yield). It's magnitude $3.4 \%$ indicated that the characters included in the path analysis explained $96.6 \%$ of the phenotypic variation in seed yield.

Table 3: Estimates of direct (diagonal) \& indirect (off diagonal) effects for different traits on seed yield at genotypic level

\begin{tabular}{|c|c|c|c|c|c|c|c|c|c|c|c|}
\hline Traits & DF & DM & CFP & PH & NPB & BPP & CPP & TSW & BM & $\mathrm{HI}$ & rg \\
\hline$\overline{D F}$ & -5.71 & 4.359 & 1.664 & -0.019 & -0.484 & 0.14 & -0.299 & -0.05 & -0.148 & 1.301 & $0.753^{* \star}$ \\
\hline DM & $\begin{array}{l}-4.84 \\
\end{array}$ & 5.15 & 0.16 & -0.01 & -0.4 & 0.1 & -0.06 & -0.05 & -0.24 & 1.07 & $0.878^{* \star}$ \\
\hline CFP & -2.6 & 0.22 & 3.65 & -0.02 & -0.17 & 0.08 & -0.67 & -0.15 & -0.04 & 0.15 & $0.429^{* \star}$ \\
\hline $\mathrm{PH}$ & -3.95 & 1.58 & 3.17 & -0.03 & -0.23 & 0.07 & -0.64 & -0.4 & -0.22 & 0.71 & 0.075 \\
\hline NPB & -4.711 & 3.489 & 1.084 & -0.011 & -0.587 & 0.151 & -0.357 & -0.296 & -0.015 & 1.735 & $0.482^{* *}$ \\
\hline BPP & -4.94 & 3.08 & 1.7 & -0.01 & -0.55 & 0.16 & -0.27 & -0.25 & -0.01 & 1.6 & 0.503 \\
\hline CPP & -2.31 & 0.4 & 3.3 & -0.02 & -0.28 & 0.06 & -0.74 & -0.42 & -0.06 & 0.71 & $0.639^{\text {** }}$ \\
\hline TSW & -0.662 & 0.612 & 1.292 & -0.026 & -0.404 & 0.094 & -0.722 & -0.43 & -0.039 & 0.799 & $0.515^{\star *}$ \\
\hline BM & -3.25 & 4.7 & 0.53 & -0.02 & -0.03 & 0.01 & -0.17 & -0.06 & -0.26 & -1.4 & 0.041 \\
\hline $\mathrm{HI}$ & -4.01 & 2.96 & 0.29 & -0.01 & -0.55 & 0.14 & -0.29 & -0.19 & 0.2 & 1.85 & $0.399^{*}$ \\
\hline
\end{tabular}

$\mathrm{DF}=$ Days to $50 \%$ flowering, $\mathrm{DM}=$ Days to $95 \%$ maturity, $\mathrm{PH}=$ plant height, $\mathrm{CFP}=$ Days to capsule filling period, $\mathrm{PB}=$ Number of primary branches per plant, BPP $=$ Number of branches per Plant, $\mathrm{CPP}=$ number of capsules per plant $\mathrm{BY}=$ Biomass yield per ha, $\mathrm{SW}=$ thousand seed weight, $\mathrm{rp}=$ phenotypic correlation with seed yield. 
Table 4: Estimates of direct (bold diagonal) and indirect (off diagonal) effects of different traits on seed yield at phenotypic level

\begin{tabular}{|c|c|c|c|c|c|c|c|c|c|c|c|}
\hline Traits & DF & DM & CFP & $\mathbf{P H}$ & NPB & BPP & CPP & TSW & BY & $\mathrm{HI}$ & $r p$ \\
\hline DF & -16.43 & -5.219 & 3.938 & 6.698 & 28.125 & -18.056 & -4.145 & -0.221 & 3.288 & 2.672 & $0.654^{\star \star}$ \\
\hline DM & -12.65 & -6.78 & 0.06 & 1.92 & 20.2 & -10.4 & -0.24 & -0.24 & 6.97 & 1.97 & $0.820^{* *}$ \\
\hline CFP & -5.03 & -0.03 & 12.87 & 9.98 & 5.6 & -7.09 & -1 & -1.67 & 0. & 0 . & 0.268 \\
\hline $\mathrm{PH}$ & -9.56 & -1.132 & 11.158 & 11.51 & 9.059 & -6. & -1 & -7.607 & 6.456 & 0.97 & 0.011 \\
\hline NPB & -12.19 & -3.61 & 1.9 & 2.75 & 37.9 & -19.36 & -6.35 & -4.9 & 0.1 & 4.23 & $0.470^{* *}$ \\
\hline BPP & -14 & -3.39 & 4.3 & 3.35 & 35. & -20 & -3.95 & -3 & 0.06 & 3.6 & 0. \\
\hline CPP & -3.762 & -0.088 & 10.631 & 9.403 & 13.305 & -4.535 & -18.1 & -8.185 & 0.758 & 1.084 & $0.509^{\star \star}$ \\
\hline TSW & -0.43 & -0.19 & 2.52 & 10.3 & 21.83 & -9.42 & -17.43 & -8.5 & 0.37 & 1.3 & $0.352^{*}$ \\
\hline BY & -6.77 & -5.92 & 0.76 & 9.31 & 0.45 & -0.15 & -1 & & 7.98 & -3.56 & 0.005 \\
\hline $\mathrm{HI}$ & -9.45 & -2.87 & 0.31 & 2.4 & 34.49 & -16.41 & -4.22 & -2.38 & -6.12 & 4.64 & $0.385^{*}$ \\
\hline
\end{tabular}

$\mathrm{DF}=$ Days to $50 \%$ flowering, $\mathrm{DM}=$ Days to maturity, $\mathrm{PH}=$ plant height, $\mathrm{PB}=$ Number of primary branch per plant, $\mathrm{PB}=\mathrm{Number}$ of primary branches per plant, BPP $=$ Number of branches per plant, $\mathrm{CPP}=$ number of capsules per plant, BY=Biomass yield per plots $=$ thousand seed weight, $\mathrm{rg}=$ genotypic correlation with seed yield .

\section{Genetic Divergence Analysis}

Description of germplasm collection for agronomical useful characters is important prerequisite for effective and efficient utilization of germplasm collection in breeding program. Significant differences among varieties for all or majority of the characters would justify further calculation of $D^{2}$ (Sharma, 1998). The $D^{2}$ values based on the pooled mean of genotypes resulted in classifying the
64 genotypes in to four distinct clusters (Figure 1). Cluster II were the largest clusters (45.31\%) containing 29 genotypes followed by Cluster I (26.56\%) which had 17 genotypes, then Cluster III that had 15 (23.44\%) genotypes and finally cluster IV (4.68\%) with 3 genotypes which had outstanding performance than any other genotypes in other clusters.

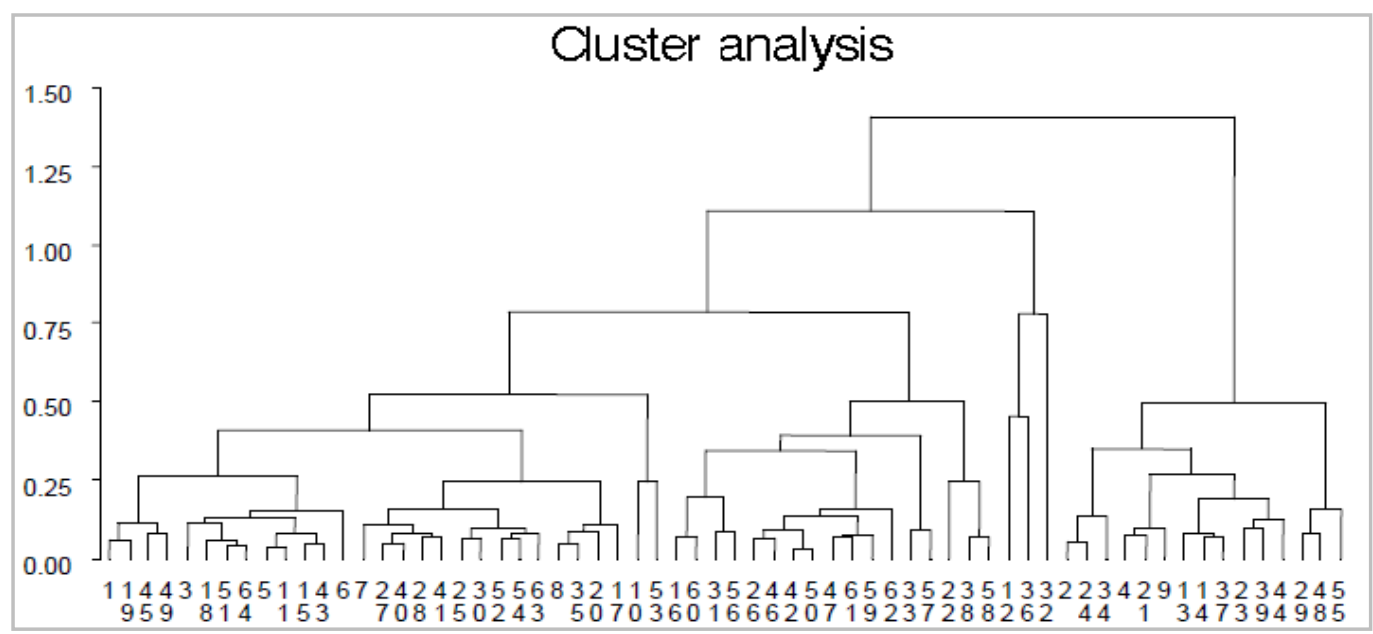

Figure 1: Dendrogram of 64 genotypes of sesame based on evaluation for 12 characters

\section{Cluster Mean Analysis}

The mean value of the 11 quantitative characters in each cluster is presented in Table 5. Cluster I consisted of fifteen genotypes having the characteristic of late flowering, late maturing, longer period of days to fill the capsule, lowest biomass and higher harvest index. Cluster
II consisted of 3 genotypes. This cluster could be characterized by longer PH, higher NPB, BPP, TSW, BY, SY and HI. Cluster III consisted of 17 genotypes characterized by longer CFP, CPP, lowest for BY and HI. Cluster IV had 29 genotypes which are characterized by the following features: Highest in $\mathrm{PH}$, lowest in SY and $\mathrm{HI}$.

Table 5: Mean values of 11 morphological characters of the four clusters for sesame genotypes

\begin{tabular}{|c|c|c|c|c|}
\hline Traits & $\mathrm{Cl}^{*}$ & $\mathrm{CII}$ & CIII & CIV \\
\hline Days to $5 \%$ flowering & 60.6 & 59.5 & 60.05 & 60.52 \\
\hline Days to $95 \%$ maturity & 135.17 & 133.5 & 134.3 & 131.16 \\
\hline Capsule filling period & 45.43 & 46.67 & 48.09 & 46.03 \\
\hline Plant height, $\mathrm{cm}$ & 102.93 & 105.3 & 103.2 & 105.66 \\
\hline Number of primary branches per plant & 2.7 & 7.3 & 2.41 & 2.21 \\
\hline Number of branches per plant & 2.9 & 7.5 & 3.12 & 2.91 \\
\hline Number of capsules per plant & 87.57 & 90.67 & 92.8 & 90.62 \\
\hline Hundred seed weight, g & 2.24 & 2.88 & 2.49 & 2.38 \\
\hline Biological yield (g/plot) & 626.2 & 1087.67 & 1200.56 & 967.57 \\
\hline Seed yield (kg/ ha) & 473.79 & 801.361 & 462.729 & 467.723 \\
\hline Harvest index & 0.24 & 0.237 & 0.136 & 0.17 \\
\hline
\end{tabular}




\section{Gadisa Hika et alo,}

Estimation of Intra and Inter-Cluster Square Distances The average intra- and inter-cluster $D^{2}$ values are presented in Table 6. Maximum average intra cluster $D^{2}$ was obtained in cluster III followed by cluster I. The lowest $\mathrm{D}^{2}$ was recorded in cluster II, which shows the presence of less genetic variability or diversity within this cluster.

Table 6: Average intra (bold) and inter cluster (off diagonal) $D^{2}$ values among four clusters in sesame genotypes

\begin{tabular}{c|c|ccc}
\hline Clusters & \multicolumn{1}{c}{ Cl } & \multicolumn{1}{c}{ CII } & \multicolumn{1}{c}{ CIII } & \multicolumn{1}{c}{ CIV } \\
\hline Cl & $\mathbf{3 . 0 4}$ & $141.63^{\star *}$ & $50.15^{\star *}$ & $42.50^{\star *}$ \\
\cline { 2 - 3 } CII & & $\mathbf{2 . 3 3}$ & $34.75^{\star *}$ & $38.36^{\star *}$ \\
CIII & & & $\mathbf{3 . 1 9}$ & 9.02 \\
CIV & & & & $\mathbf{2 . 6 5}$ \\
\hline
\end{tabular}

$x^{2}=22.36$, and 27.69 at $5 \%$ and $1 \%$ probability level respectively

The $x^{2}$ - test for the four clusters indicated that there was a statistically significant difference between pairs of clusters except cluster III with IV. The highest average inter-cluster $D^{2}$ value was recorded between cluster I and cluster II followed by cluster I and cluster III and cluster I and cluster IV which had shown these clusters were genetically more divergent from each other than any other clusters.

Minimum inter-cluster distance was observed between cluster III and cluster IV indicating that genotypes in these clusters were not genetically diverse or there was little genetic diversity between these clusters. This signifies that, crossing of genotypes from these two clusters might not give higher hetrotic value in $\mathrm{F} 1$ and narrow range of variability in the segregating F2 population. Maximum
Sci. Technol. Arts Res. J., Oct-Dec 2014, 3(4): 01-09

genetic recombination is expected from the hybridization of the parents selected from divergent cluster groups. Therefore, maximum recombination and segregation of the progenies is expected from crosses involving parents selected from cluster II and IV followed by I and cluster III; however the breeder must specify his/her objectives in order to make best use of the characters where the characters are divergent.

\section{Principal Component Analysis}

The principal component analysis (Table 7) revealed that four principal components PC1, PC2, PC3, and PC4 with eigen values $3.36,2.94,1.68$, and 1.28 , respectively, have accounted for $66 \%$ of the total variation. The first two principal components PC1 and PC2 with values of $24 \%$ and $21 \%$, respectively, contributed more to the total variation. Therefore, in this study, differentiation of the genotypes into different cluster was because of a cumulative effect of a number of characters rather than the contribution of specific few characters. Agronomic characters having relatively higher value in the first principal component (PC1) were number of branch per plant, seed and biomass yield, harvest index and thousand seed weight had more contribution to the total diversity and they were responsible for the differentiation of the genotypes. Characters like capsule filling period, thousand seed weight and biomass yield per plot had contributed a lot for principal component (PC2); number of branches per plant, days to maturity and capsule filling period had contributed in the third principal component (PC3); days to $50 \%$ flowering, days to maturity, harvest index ,number of capsule filling period, seed yield and number of capsules per plant in the fourth principal component (PC4); were the major contributors to each principal components (PC).

Table 7: Eigenvectors and eigen values of the first four principal components (PCs) for different characters of sesame genotypes

\begin{tabular}{lllll}
\hline Traits & PC1 & PC2 & PC3 & PC4 \\
\hline Days to 50\% flowering & -0.014 & -0.021 & 0.104 & 0.154 \\
Days to maturity & 0.034 & 0.037 & 0.327 & 0.624 \\
Capsule filling period & -0.027 & 0.193 & 0.119 & 0.220 \\
Plant height (cm) & 0.083 & -0.058 & -0.505 & 0.097 \\
Number of primary branches per plant & 0.397 & 0.168 & 0.344 & -0.190 \\
Number of branches per plant & 0.348 & 0.163 & 0.419 & -0.124 \\
Number of capsules per plant & -0.028 & 0.112 & -0.012 & 0.643 \\
Thousand Seed weight (g) & 0.307 & 0.251 & -0.187 & -0.085 \\
Biomass yield per plot (g/plot) & 0.055 & 0.544 & -0.188 & -0.005 \\
Harvest Index & 0.244 & -0.483 & 0.007 & 0.128 \\
Seed yield (kg/ ha) & 0.490 & 0.044 & -0.220 & 0.119 \\
\hline Eigen value & 3.36 & 2.94 & 1.68 & 1.28 \\
Difference & 0.414 & 1.26 & 0.408 & 0.08 \\
Percent of total variance & 24 & 21 & 12 & 9 \\
Cumulative percent of total variance & 24 & 45 & 57 & 66
\end{tabular}

$\mathrm{DF}=$ Days to $50 \%$ flowering, $\mathrm{DM}=$ Days to $95 \%$ maturity, CFP $=$ Capsule filling period, $\mathrm{PH}=\mathrm{Plant}$ height $(\mathrm{cm})$, $\mathrm{BPP}=$ Number of branches per plant, $\mathrm{PB}=$ Number of primary branch per plant, CPP $=$ Number of capsules per plant, $\mathrm{SY}=$ seed yield $(\mathrm{kg} / \mathrm{ha}, \mathrm{BYp}=$ Biomass yield per plot $(\mathrm{g} / \mathrm{plot}), \mathrm{HI}=$ Harvest index, $\mathrm{SW}=1000$ seed weight $(\mathrm{g})$.

\section{Quality Characteristics of Sesame Genotypes}

Seed color is one of the most important quality traits of sesame for its commercial value. There are different color of sesame seed i.e. white, black, brown, red, and grey and others. Five types of colors had been identified in the studied genotypes namely white, black and brown, grey and red with varying frequencies (Figure 2). 


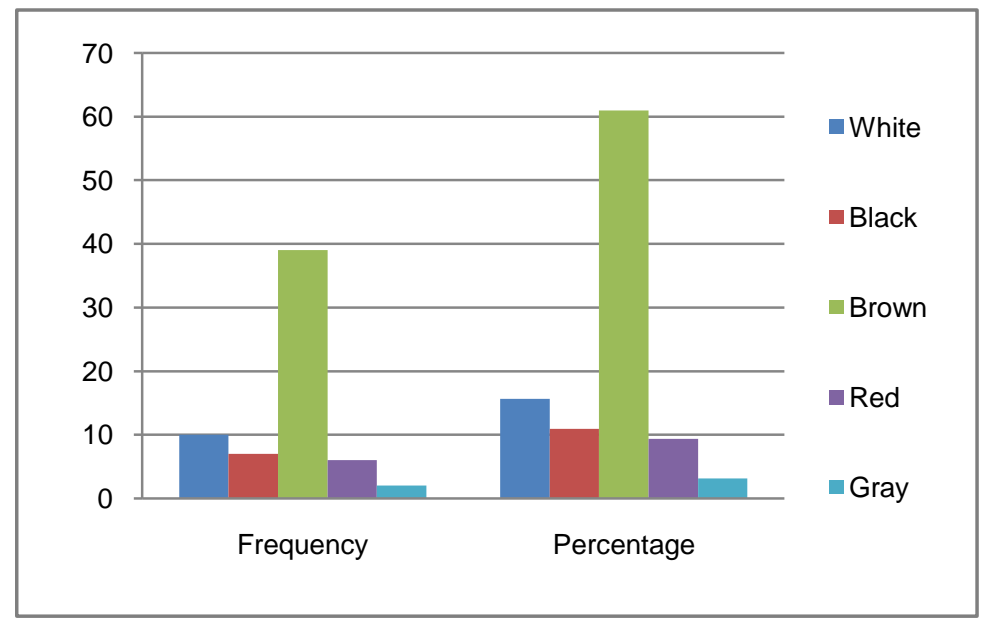

Figure 2: Frequency of seed colors among the 64 genotypes of sesame

\section{DISCUSSION}

Seed yield is the result of many yield contributing characters which are interdependent among themselves including seed yield. The analysis of the relationship among these characters and their associations with seed yield is essential to establish selection criteria (Singh et al., 1990). In the present study the magnitudes of genotypic correlation coefficients for most of the characters were higher than their corresponding phenotypic correlation coefficients, which indicate the presence of inherent or genetic association among various characters. Characters including DF, DM, CFP, PB, BPP, CPP, TSW and HI were found to be strongly associated with seed yield. Number of capsule per plant had positive and significant genotypic and phenotypic correlations with CFP, PH, PB and TSW; and it had positive and significant correlation with days to $50 \%$ flowering, at genotypic level only. Therefore, any improvement of these characters would result in a substantial increment in seed yield. These results are corroborated with the finding of Yirgalem et al. (2013), who reported that $\mathrm{HI}$ was strongly associated with seed yield both at genotypic and phenotypic levels. Similarly, others reported (Sakila et al., 2000; Kathiresan and Gnanamurthy, 2000) that number of capsules per plant, days to $50 \%$ flowering and plant height were positively correlated with seed yield. This means number of capsules increases as the plant height and number of branches per plant increases. Similar results were reported by Reddy and Ramachandraiah (1990), i.e. number of capsules per plant was positively correlated with number of branches per plant, plant height and days to $50 \%$ flowering. Biomass yield had positive and significant genotypic and phenotypic correlations with days to $50 \%$ flowering, days to $90 \%$ maturity, and plant height while it had negative and significant correlation with harvest index. Higher biomass yield can be obtained as the results of longer vegetative periods. Thousand seed weight had significant and positive genotypic and phenotypic correlations with capsule filling period, plant height and number of branches per plant, number of primary branches per plant; and it had positive and significant correlations with harvest index at genotypic level only. Generally, positive and significant association of pairs of characters at phenotypic and genotypic level justified the possibility of simultaneous improvement of traits through different breeding strategies.
When more characters are involved in correlation study, it becomes difficult to ascertain the characters which really contribute to yield. The path coefficient analysis under such situations helps to determine the direct contribution of these characters and their indirect contributions via other characters. In the present study, positive and high direct effect was exerted on seed yield by DM, CFP, BPB, and $\mathrm{HI}$ while negative and high direct effect was exerted by DF, NPB and CPP at genotypic level. The high significant correlation coefficient between seed yield and DF was due to its high indirect effects through DM and CFP on seed yield. The high positive correlation coefficient between seed yield and CPP was due the large indirect effects of CFP and HI. Characters including DM, CFP and $\mathrm{HI}$ had high positive direct effects on seed yield and also they had strong correlations with seed yield indicating the most important yield related traits at genotypic level. Positive and high direct effects on seed yield were exerted by CFP, $\mathrm{PH}, \mathrm{NPB}, \mathrm{BY}$ and $\mathrm{HI}$ at phenotypic level while negative and high direct effect on seed yield were exerted by DF, DM BPP, CPP, and TSW. The positive and significant correlation coefficients of DF and DM with SY were due to their positive indirect effects through CFP, PH, NPB, BY and HI. The present findings are in agreement with the results of (Yingzhong and Yishou, 2002; Yirgalem et al., 2013) in which days to 50\% flowering had negative direct effect while capsule filling period exerted positive direct effect on seed yield. Both CFP, NPB, and $\mathrm{HI}$ had strong positive associations as well positive direct effects on SY indicating they are more related than other traits to SY at phenotypic level.

Cluster analysis showed that the 64 sesame genotypes were grouped in to four classes. Cluster I genotypes showed the characteristic of late flowering, late maturity, took longer period to fill the capsules and low harvest index. Cluster II genotypes showed characteristics of longer $\mathrm{PH}$, higer NBP, BPP, TSW, highest SY and BY, and $\mathrm{HI}$. Cluster III genotypes showed characteristics of longer period to fill the capsules, least BY and HI. Cluster IV had 29 genotypes characterized by highest in $\mathrm{PH}$, and lowest in SY and $\mathrm{HI}$.

Maximum average intra cluster $D^{2}$ was obtained in cluster III followed by cluster I. The lowest $D^{2}$ was recorded in cluster II, which shows the presence of less 


\section{Gadisa Hika et alo,}

genetic variability or diversity within this cluster. The highest average inter-cluster $D^{2}$ value was recorded between cluster I and cluster II followed by cluster I and cluster III indicating these pairs of clusters were genetically more divergent from each other than other clusters. According to Ghaderi et al. (1984) increasing parental distance implies a great number of contrasting alleles at the desired loci, and then to the extent that these loci recombine in the $\mathrm{F} 2$ and $\mathrm{F} 3$ generations following a cross of distantly related parents, the greater will be the opportunities for the effective selection for yield factors. Maximum genetic recombination is expected from the hybridization of the parents selected from distant groups. Therefore, maximum recombination and segregation of the progenies is expected from crosses involving parents selected from cluster I and II followed by I and cluster III; however the breeder must specify his/her objectives in order to make best use of the characters where the characters are divergent.

Principal component analysis (PCA) is one of the multivariate statistical techniques which is a powerful tool for investigating and summarizing underlying trends in complex data structures (Legendre and Legendre, 1998). Principal component analysis reflects the importance of factors majorly contributing to the total variation at each axis for differentiation (Sharma, 1998). The principal component analysis revealed that four principal components PC1, PC2, PC3, and PC4 have accounted for $66 \%$ of the total variation. According to Chahal and Gosal (2002), characters with largest absolute values closer to unity with in the first principal component influence the clustering more than those with lower absolute values closer to zero. Therefore, in this study, differentiation of the genotypes into different cluster was because of a cumulative effect of a number of characters rather than the contribution of specific few characters. Agronomic characters having relatively higher value in the first principal component (PC1) were number of branch per plant, seed yield, biomass yield, harvest index and thousand kernel weight and they were responsible for the differentiation of the four clusters. Characters like capsule filling period, thousand seed weight and biomass yield per plot had contributed a lot for principal component (PC2). Seed color is one of the most important quality traits of sesame for its commercial value. There are different color of sesame seed i.e. white, black, brown, red, and grey and others. Five types of colors had been identified in the studied genotypes namely white, black and brown, grey and red with varying frequencies; and brown seed color is the dominant one in the genotypes.

\section{CONCLUSION}

Seed yield had positive and significant genotypic and phenotypic correlations with all traits except with $\mathrm{PH}$ and BY. Therefore, they are important yield related characters and can be used for yield improvement in sesame breeding program. Positive and high direct effects were exerted by DM, CFP, BPB, and $\mathrm{HI}$ on seed yield while negative and high direct effects were exerted by DF, NPB and CPP. Characters including DM, CFP and $\mathrm{HI}$ had high positive direct effects and strong correlation with seed yield indicating that they are most important yield related traits at genotypic level. Positive and high direct effects on seed yield were observed at phenotypic level by CFP, $\mathrm{PH}$, NPB, BY and $\mathrm{HI}$ while negative and high direct effects on seed yield were observed by DF, DM BPP, CPP, and TSW. Traits including CFP, NPB, and $\mathrm{HI}$ had strong
Sci. Technol. Arts Res. J., Oct-Dec 2014, 3(4): 01-09

positive correlations as well positive direct effects on SY indicating they are more related to SY at phenotypic level.

Genetic distance analysis is very important for hybridization program to get better yield and best recombinant parents. The maximum inter cluster square distance $\left(D^{2}\right)$ was recorded between cluster I and II followed by cluster I and III. Hence crossing involving parents from cluster I with II and cluster I and III may exhibit high hetrotic values in F1 generation and could give transgressive segregants in proceeding generations. The principal component analysis revealed that four principal components (PC1, PC2, PC3, and PC4) explained or accounted for about $66 \%$ of the total variation existed among the genotypes. The dominant seed color observed was brown followed by white in the genotypes. The advantage and relation of color types and association with seed yield and fatty acid components can be investigated in the future in another experiment. This study generally indicated that there was significance genetic variability or divergence among the genotypes. Thus, there is enormous opportunity to go for direct selection as well as crossing of distant parents to improve specific traits in subsequent selections of the sesame genotypes.

\section{ACKNOWLEDGEMENTS}

The authors are grateful to the Institute of Biodiversity Conservation of Ethiopia (IBC/E) for providing the necessary materials.

\section{REFERENCES}

Ashri, A. (1988). Sesame breeding: Objectives and approaches, Pp. 157-164. In: Omran, A. (Ed.), Oil Crops: Sunflower, Linseed and Sesame. International Development Research Center (IDRC), Ottawa, Canada.

Bedigian D., Harlan, J. R. (1986). Evidence for the cultivation of sesame in the ancient world. Economic Botany 40:137154.

Brar, G.S., Ahuja, K.L. (1979). Sesame: its culture, genetics, breeding and biochemistry. PP. 245-313. In: Malik, C.P. (Ed.), Annual Review of Plant Science, Kalyani publishers, New Delhi.

Burton, G.W., de Vane, E.H. (1953). Estimating heritability in Tall Fescue (Festuca arundinacea) from replicated clonal material. Agronomy Journal 45: 481-487.

Chahal, G.S., Gosal, S.S. (2002). Principles and Procedures of Plant Breeding: Biotechnology and Conventional Approaches. Narosa Publishing House, New Delhi, 604 $\mathrm{Pp}$.

CSA (Central Statistical Authority) (2011). Central Agricultural Census Commission, Ethiopian Agricultural Sample Enumeration.

Dabholkar, A. R. (1992). Elements of Biometrical Genetics. Concept publishing Company. New Dehli, 431Pp.

Dewey, D.R., Lu, K.H. (1959). A correlation and path coefficient analysis of components of crested wheat grass seed production. Agronomy Journal 51: 515-518.

FAO Production Year Book (1995). Food and Agriculture Organization of the United Nations, Rome, vol. 49, p. 113.

FAO Production Year Book (2005). Food and Agriculture Organization of the United Nations-Rome, Vol. 40, p. 116.

Ghaderi, A., Adams, M.W., Nassib, A.M. (1984). Relationship between genetic distance and heterosis for yield and 


\section{Gadisa Hika et al.,}

morphological traits in dry edible bean and faba bean. Crop Science 24:37-42.

Ercan, A.G., Taskin, M., Turgut, K. (2004). Analysis of genetic diversity in Turkish sesame (Sesamum indicum L.) populations using RAPD markers. Genetic Resources and Crop Evolution 51: 599-607.

Kathiresan, G., Gnanmurthy, P. (2000). Studies on seed yield-contributing characters in sesame. Sesame Safflower Newsletter 15: 39-42.

Kobayashi, T. (1981). The wild and cultivated species in the genus Sesamum. Sesame: Status and improvement. Proceedings of Expert Consultation, Rome, Italy, 8-12 December, 1980. FAO Plant Production and Protection Paper 29, pp 157-163.

Legendre, P., Legendre, L. (1998). Numerical Ecology, 2nd edtion, Amsterdam, Elsevier, 853Pp.

Mahalanobis, P.C. (1936). The generalized distance in statistics. Proceeding of Indian National Institute of Science 2: 49-55.

Miller, P.A., Williams, C., Robinson, H. F., Comstock, R.E. (1958). Estimates of genotypic and Environmental variances and co-variances in upland cotton and their implications in selection. Agronomy Journal 50:126-131.

Nath, R, Chakraborty, P.K., Chakraborty, A. (2000). Effect of microclimatic parameters at different Sowing dates on capsule production of sesame (Sesamum indicum L.) in a tropical humid region. Journal of Agronomy and Crop Science 184: 247-252.

Nayar, N.M, Mehra K.L. 1970. Sesame: Its uses: botany, cytogenetics, and origin. Economic Botany 24: 20-31.

Reddy, C.D.R., Ramachandraiah, D. (1990). Character association and path analysis in sesamum parents and their F1 hybrids. Orissa Journal of Agricultural Research 3: $37-44$

Robertson, A. (1959). The sampling variance of generic correlation coefficient. Biometrics 15: 469-485.

Sakila, M., Ibrahim, S.M., Kalamani, A., Backiyarani, S. (2000). Correlation studies in sesame (Sesamum indicum L.), Pp. 26-28. In: Fernández-Martínez, J. (Ed.), Sesame and Safflower News Letter No. 15, Institute of Sustainable Agriculture (IAS), CSIC, Apartado 4084, Córdoba, Spain.
Sci. Technol. Arts Res. J., Oct-Dec 2014, 3(4): 01-09

Salunkhe, D.K., Desai, B.B. (1986). Post-Harvest biotechnology of oilseeds. CRC Press, Boca Raton, Florida, Pp. 105-117.

Sastri, A.B. (1974). Path analysis of yield components in Tobacco. Indian Journal of Genetics 34: 57-58.

SAS (Statistical Analysis System). (2002). Version 9.0, USA.

Singh, K.B., Geletu Bejiga, Malhorta, R.S. (1990). Association of some characters with seed yield in chick pea collection. Euphytica 49: 83-88

Singh, R.K., Chaudhary, B.D. (1977). Biometrical Methods in Quantitative Genetics Analysis, Kalyani publishers, New Delhi, $318 \mathrm{Pp}$.

Singh, T.P., Singh, K.B. (1973). Association of grain yield and its components in segregating populations of green gram. Indian Journal of Genetics 33:112-117.

Sharma, J.R. (1998). Statistical and Biometrical Techniques in Plant Breeding. New Age International Publisher, New Dehli, 432 Pp.

Uzo, J.O., Ojiake, G.V. (1981). Breeding and selection method for sesame on the basis of assessment of major Nigerian sesame strains, F1 hybrids and segregating generations. In: sesame-status and improvement. Proceedings of expert consultation. Rome.

Yermanos, D.M., Hemstreet, S., Saeeb, W., Huszar, C.K. (1972). Oil content and composition of the seed in the world collection of sesame introductions. Journal of American Oil Chemistry Society 49:20-23.

Yingzhong, Z., Yishou, W. (2002). Genotypic correlation and path coefficient analysis in sesame. Sesame and Safflower News Letter 17:40-45.

Yirgalem Tesfaye, Sintayehu Alamirewu, Geremew Terefe (2013). Assessment of genetic variability, genetic advance, correlation and path analysis for morphological traits in sesame genotypes. International Journal of Plant Breeding and Genetics 7: 21-34.

Zhang, H., Miao, H., Wang, L. Qu. L., Liu, H., Wang, Q., Yue, M. (2013). Genome sequencing of the important oilseed crop Sesamum indicum L. Genome Biology 14:1-9. 